\title{
Time domain reflectometry-measuring dielectric permittivity to detect soil non-acqeous phase liquids contamination-decontamination processes
}

\author{
A. Comegna, ${ }^{1}$ A. Coppola, ${ }^{2}$ G. Dragonetti, ${ }^{3}$ N. Chaali, ${ }^{1}$ A. Sommella ${ }^{4}$ \\ ${ }^{1}$ School of Agricultural Forestry Food and Environmental Sciences (SAFE), University of \\ Basilicata, Potenza, Italy; ${ }^{2}$ Department of European and Mediterranean Cultures-Architecture, \\ Environment, Cultural Heritage (DiCEM), Hydraulics and Hydrology Division, University of \\ Basilicata, Matera, Italy; ${ }^{3}$ Mediterranean Agronomic Institute, Land and Water Division, IAMB, \\ Bari, Italy; ${ }^{4}$ Division of Water Resources Management, University of Naples "Federico II", Italy
}

\begin{abstract}
Contamination of soils with non-aqueous phase liquids (NAPL) constitutes a serious geo-environmental problem, given the toxicity level and high mobility of these organic compounds. To develop effective decontamination methods, characterisation and identification of contaminated soils are needed. The objective of this work is to explore the potential of dielectric permittivity measurements to detect the presence of NAPLs in soils. The dielectric permittivity was measured by Time Domain Reflectometry method (TDR) in soil samples with either different volumetric content of water $\left(\theta_{\mathrm{w}}\right)$ and NAPL $\left(\theta_{\mathrm{NAPL}}\right)$ or at different stages during immiscible displacement test carried out with two different flushing solutions. A mixing model proposed by Francisca and Montoro, was calibrated to estimate the volume fraction of contaminant present in soil. Obtained results, showed that soil contamination with NAPL and the monitoring of immiscible fluid displacement, during soil remediation processes, can be clearly identified from dielectric measurements.
\end{abstract}

\section{Introduction}

Subsurface contamination of soil and groundwater with organic compounds from waste disposal sites, industrial spills, gasoline stations, mine tailings and industrial processes constitutes a serious geoenvironmental problem. The detrimental effects are limited not only to deterioration of chemical, physical and mechanical properties of soils,

Correspondence: A. Comegna, School of Agricultural Forestry Food and Environmental Sciences (SAFE), University of Basilicata, Potenza, Italy. E-mail: alessandro.comegna@unibas.it

Key words: soil-NAPL-water mixtures; dielectric permittivity; mixing models, remediation processes.

(C) Copyright A. Comegna et al., 2013

Licensee PAGEPress, Italy

Journal of Agricultural Engineering 2013; XLIV(s2):e167

doi:10.4081/jae.2013.s2.e167

This article is distributed under the terms of the Creative Commons Attribution Noncommercial License (by-nc 3.0) which permits any noncommercial use, distribution, and reproduction in any medium, provided the original author(s) and source are credited. but also constitute a real risk to human health and the well-being of other living species.

Non-aqueous phase liquids (NAPLs), are organic compounds immiscible with water. They have low solubility that may still be several orders of magnitude higher than that of acceptable drinking water standards. NAPLs can be further subdivided into those that are denser than water (DNAPLs) and those that are lighter than water (LNAPLs). Chlorinated solvents such as trichloroethylene (TCE) and tetrachloroethylene (PCE) and polychlorinated biphenyl oils (PCBs) are common examples of DNAPLs. Hydrocarbon fuels such as gasoline, kerosene and jet fuels are common LNAPL contaminants which pollute the environment extensively (Illangasekare, 1998; Jury and Horton, 2004).

Following a near-surface release, NAPLs penetrate the subsurface as an immiscible oil phase that migrates in response to gravity and capillary forces. This results in substantial sensitivity to the local distribution of soil and aquifer properties (e.g. permeability and porosity) beneath the source (Gerhard et al., 2007). As a result, the NAPL body (e.g. the source zone) is often expected to exhibit a complex heterogeneous distribution of both mobile pools (i.e. connected-phase accumulations) and immobile residuals (i.e. disconnected blobs and ganglia (Mercer and Cohen, 1990).

The remediation of contaminated soil sites requires knowledge of the contaminant distribution in the soil profile and groundwater. Methods commonly used to characterize contaminated sites are coring, soil sampling and the installation of monitoring wells for the collection of groundwater samples (Mercer and Cohen, 1990).

Given the high cost of the above methods, other non-invasive methods have been sought to extensively characterize sites and provide volume-averaged properties that support localized measurements provided by sampling and coring. Indirect detection with geophysical methods (e.g. radar, resistivity and conductivity) offers an attractive alternative (Redman et al., 1991). In particular, the time domain reflectometry (TDR) technique has been proposed as potentially exhibiting sufficient sensitivity and lateral and vertical resolution for characterization of saturation of NAPLs $\left(\theta_{N A P L}\right)$. This is because commonly encountered NAPLs have a dielectric permittivity of 2-10 versus 81 for water, 1 for air, and 4-5 for soil mineral grains (Ajo-Franklin et al., 2006).

Most studies have demonstrated estimation of $\theta_{N A P L}$ essentially in saturated coarse-grained media (Redman and DeRyck, 1994; Chenaf and Amara, 2001; Persson and Berndtsson, 2002; Haridy et al., 2004; Mohamed and Said, 2005; Ajo-Franklin et al., 2006; Moroizumi and Sasaki, 2006; Francisca and Montoro, 2012). Little is known about the dielectric behaviour of contaminated fine-grained soils. The complexity of these soils, arises due to polarization of the diffuse-double layer, whereas coarse-grained soils do not possess polarization at which most of the cited studies have been conducted. Moreover, in these studies 
estimation of $\theta_{N A P L}$ using TDR measurements of dielectric properties relies greatly on various mixing models (van Dam et al., 2005) relating the measured dielectric permittivity to the volume fractions of the pore fluids and various soil phases such as solid, water, air and NAPLs.

New laboratory-controlled experiments are still needed to extend the above research on TDR identification of organic contaminated soils by dielectric permittivity measurements. The experimentation strategy of the present research emphasized, in a preliminary approach, the study of the potential use of TDR to monitor or map $\theta_{\mathrm{f}}\left(=\theta_{w}+\theta_{N A P L}\right)$ in soil. The specific aims include: i) evaluation of correlations between $\theta_{f}$ in variable saturated volcanic Vesuvian soil, and dielectric permittivity, ii) examination and validation of the mixing model provided by Francisca and Montoro (Francisca and Montoro, 2012) for predicting the dielectric permittivity of contaminated soil; iii) exploration of the potential application of electromagnetic waves to evaluate the effect of contaminant removal in soil in context.

\section{TDR and complex dielectric permittivity of soil}

The time domain reflectometry technique is a widely accepted geophysical method to estimate the complex dielectric permittivity $\left(\varepsilon^{*}\right)$ of the soil. The complex dielectric permittivity consists of two parts, a real and an imaginary part, and can be expressed by the relation of Ledieu (Ledieu et al., 1986):

$\varepsilon^{*}=\varepsilon^{\prime}+i\left[\varepsilon^{\prime \prime}+\frac{\sigma}{\omega \varepsilon_{0}}\right]$

where $\varepsilon^{*}$ is the complex dielectric permittivity of the medium, $\varepsilon$ ' is the real part (which represents the polarizability of the material), $i$ is the imaginary unit $(=\sqrt{-1}), \varepsilon$ " is the imaginary part (which captures the losses due to conduction and polarization), $s$ (Siemens/m) is the zero frequency conductivity, $\mathrm{w}$ (radians/s) is the angle frequency and $\varepsilon_{0}$ $\left(=8.85^{*} 10^{-12} \mathrm{Farads} / \mathrm{m}\right)$ is the permittivity in free space.

At the highest effective frequency of the TDR Tester (200 MHz to 1.5 $\mathrm{GHz}$ ) the complex dielectric permittivity $\varepsilon^{*}$ is considered to represent the real part only ( $\varepsilon^{\prime}$, Heimovaara et al., 1994). Besides, in the frequency range transmitted from the TDR instrument the $\varepsilon^{\prime}$ of most soil is almost independent of frequency.

Without introducing serious errors, under these assumptions, the propagation velocity $(v)$ of electromagnetic waves through an homogeneous medium can be expressed as:

$$
v=\frac{c}{\sqrt{\varepsilon^{\prime}}}
$$

where $c\left(=3 \bullet 10^{8} \mathrm{~m} / \mathrm{s}\right)$ is the velocity of an electromagnetic wave in free space (Topp et al., 1980).

\section{Materials and methods}

\section{Soil properties}

The soil used for this study was sampled from an Ap horizon of a soil pedologically classified as Andosol, localized in Campania region (Italy). In Table 1 we have also exploited the main physico-chemical soil properties.

The soil texture was determined using hydrometer and sieving analysis (Day, 1965); organic content (OC) was determined by WalkleyBlack method (Allison, 1965), The specific surface area $\left(S_{e}\right)$ was determined with ethylene glycol monoethyl ether (Carter et al., 1986).

\section{Dielectric permittivity measurement of soil-NAPL mixtures}

A first group of experiments refers to dielectric permittivity measurement conducted on mixtures with known different volumetric content of water $\left(\theta_{w}\right)$ and NAPL $\left(\theta_{N A P L}\right)$.

\section{Experimental setup}

The experimental setup consists of an excitation unit constituted by a TDR signal generator (Tektronix 1502C) and a three-wire TDR probe, with wave guides $15 \mathrm{~cm}$ long, connected to the signal generator by a coaxial cable $2 \mathrm{~m}$ long. The reflected signals are collected by a PC-based data acquisition and processing system. The reflected signal carries the signature of the sample under study. Estimation of $\varepsilon^{\prime}$ was calculated from the signal using Win-TDR software (developed by the Soil Physics Group at Utah State University). Figure 1 gives a picture of the dielectric measurement system used in these experiment.

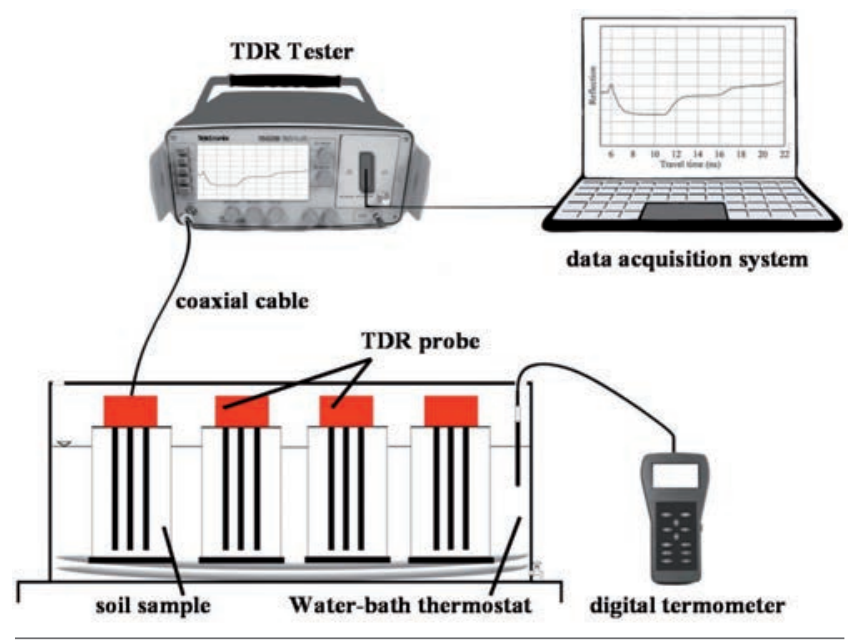

Figure 1. Experimental setup used in the experiment.

Table 1. Main physico-chemical properties of the soil.

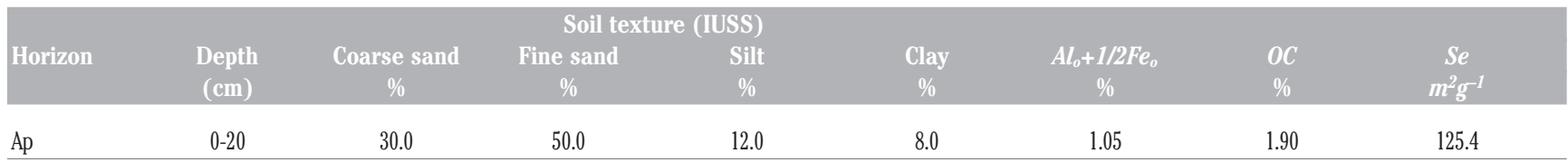




\section{Sample preparation and testing procedures}

Soil samples were oven dried at $105^{\circ} \mathrm{C}$ and passed through a $2 \mathrm{~mm}$ sieve. Corn oil, a non-volatile and non-toxic LNAPL, was used as soil contaminant. The dielectric permittivity and density of the oil were 3.2 (at $25^{\circ} \mathrm{C}$ ) and $0.905 \mathrm{~g} / \mathrm{cm}^{3}$ respectively. Known amounts of soil, water and oil were mixed together, shaken and then kept for 24 hours in sealed plastic bags to avoid any evaporation and to ensure a uniform distribution of oil and water within the sample, and good oil and water adsorption by the soil matrix. The soil is then placed in PVC soil containers of cylindrical geometry ( $16 \mathrm{~cm}$ high and $9.5 \mathrm{~cm}$ in diameter). In all, there were 40 oil-contaminated soil samples, used for a full factorial analysis presented in Table 2.

For all tests the soil was placed in the PVC containers in several steps during which it was compacted until a $1.09 \mathrm{~g} / \mathrm{cm}^{3}$ bulk density was attained. At each step the compacted surface was scraped to avoid the appearance of plane boundaries which give the sample a stratified behaviour responsible for parasitic reflections on the TDR signal. Soil samples were kept at a fairly constant temperature $\left(25^{\circ} \mathrm{C}\right)$ through the TDR measurements using a water-bath thermostat.

\section{Dielectric permittivity measurements of soil-NAPL mixtures} flushed with washing solution

A second group of experiments refers to dielectric permittivity measurements conducted in soil samples initially contaminated with NAPL and then flushed with two different washing solutions.

\section{Experimental setup}

The experimental setup consist of: i) a Techtronix cable tester; ii) a three-wire TDR probe with wave guides $15 \mathrm{~cm}$ long inserted vertically into the soil samples; iii) a testing cell of $8 \mathrm{~cm}$ in diameter and $16 \mathrm{~cm}$ high; iv) a peristaltic pump for upward injection of washing solution. Figure 2 gives a picture of experimental system used in these experiments.

\section{Sampling preparation and testing procedures}

Soil columns tests were carried out employing the following procedure: i) two soil columns were contaminated with corn-oil (by following the same procedure described in section 3.2.2) to obtain a saturation degree $\left(\theta_{N A P L}\right)$ close to 0.3 , ii) upward injection of several flushing volumes $N_{f}$ (defined as the volume of displacing fluid $V_{d}$ with respect to volume of soil sample $V$ ) of two washing solutions: a) distilled water; b) distilled water (90\%) with commercial detergent (1\%) and methanol (9\%) were supplied at a rate $q=1.5 \mathrm{~cm}^{3} / \mathrm{min}$, which corresponds to a darcian velocity $v=6.0 \mathrm{~cm} / \mathrm{h}$; iii) the out coming fluid, from the soil columns was collected, water and oil was separated and the amount of oil that is remediated from the soil is recorded.

\section{Mixing models}

In the present study, from among the many physical models of dielectric permittivity that describe soil as a mixture of particles, water and air, the a model was used (Roth et al., 1990).

$\varepsilon^{\prime}=\left[\sum_{i=1}^{n} V_{i} \varepsilon_{i}^{\alpha}\right]^{1 / \alpha}$

where $\varepsilon^{\prime}$ is the permittivity of the mixture, $\varepsilon_{i}$ and $V_{i}$ are the permittivity and volume of the " $i$ " phase respectively, the exponent a is an empirical constant related to the geometry of the grains and their spatial distri-

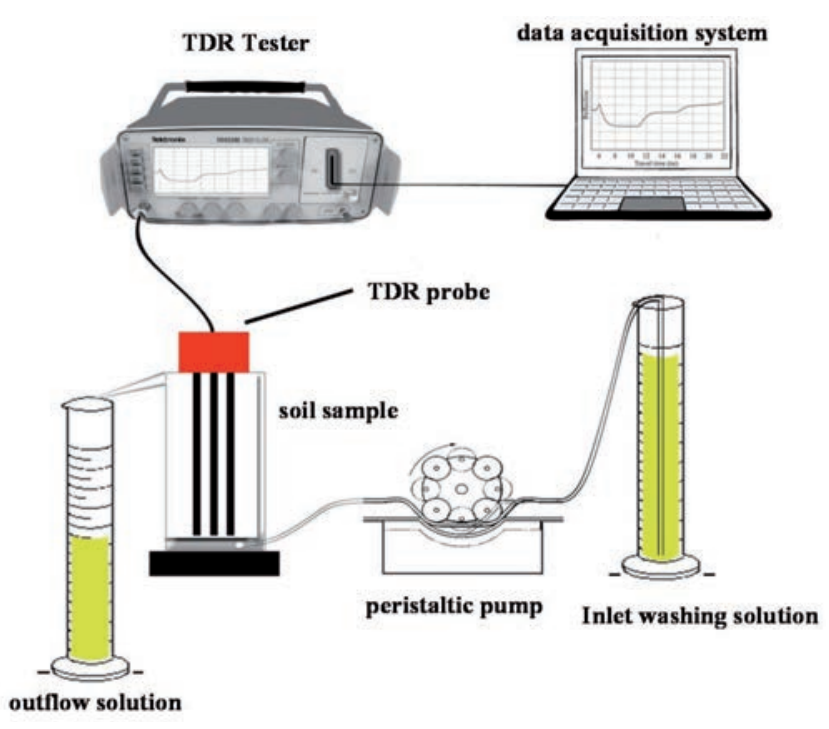

Figure 2. Experimental setup used in the NAPL removal experiment.

Table 2. Combinations of moisture volume $\left(\mathrm{V}_{\mathrm{w}}\right)$ and NAPL volume $\left(\mathrm{V}_{\mathrm{NAPL}}\right)$ at fixed values of volume fraction of NAPL $(\beta)$.

\begin{tabular}{|c|c|c|c|c|c|c|c|c|c|c|c|c|c|}
\hline \multirow{2}{*}{$\begin{array}{l}\text { volumetric fluid } \\
\text { content } \theta_{\mathrm{f}}\end{array}$} & \multirow{2}{*}{$\begin{array}{l}\text { volume of fluids } \\
\qquad\left(\mathrm{cm}^{3}\right)\end{array}$} & \multicolumn{5}{|c|}{ relative volume of NAPL in water: $\beta$} & \multirow{2}{*}{$\begin{array}{c}\text { volumetric fluid } \\
\text { content } \theta_{\mathrm{f}}\end{array}$} & \multirow{2}{*}{$\begin{array}{l}\text { volume of fluids } \\
\qquad\left(\mathrm{cm}^{3}\right)\end{array}$} & \multicolumn{5}{|c|}{ relative volume of NAPL in water: $\beta$} \\
\hline & & 1 & 0.75 & 0.5 & 0.25 & 0 & & & 1 & 0.75 & 0.5 & 0.25 & 0 \\
\hline \multirow{2}{*}{0.05} & $V_{w}$ & 0 & 13 & 27 & 40 & 53 & \multirow[t]{2}{*}{0.025} & $V_{w}$ & 0 & 67 & 133 & 200 & 267 \\
\hline & $\mathrm{V}_{\mathrm{NAPL}}$ & 53 & 40 & 27 & 13 & 0 & & $\mathrm{~V}_{\mathrm{NAPL}}$ & 267 & 200 & 133 & 67 & 0 \\
\hline \multirow[t]{2}{*}{0.10} & $v_{w}$ & 0 & 27 & 53 & 80 & 107 & \multirow[t]{2}{*}{0.30} & $V_{w}$ & 0 & 80 & 160 & 240 & 320 \\
\hline & $\mathbf{V}_{\text {NAPL }}$ & 107 & 80 & 53 & 27 & 0 & & $\mathrm{~V}_{\mathrm{NAPL}}$ & 320 & 240 & 160 & 80 & 0 \\
\hline \multirow[t]{2}{*}{0.15} & $V_{w}$ & 0 & 40 & 80 & 120 & 160 & \multirow[t]{2}{*}{0.35} & $V_{w}$ & 0 & 93 & 187 & 280 & 373 \\
\hline & $\mathrm{V}_{\text {NAPL }}$ & 160 & 120 & 80 & 40 & 0 & & $\mathbf{V}_{\text {NAPL }}$ & 373 & 280 & 187 & 93 & 0 \\
\hline \multirow[t]{2}{*}{0.20} & $V_{w}$ & 0 & 53 & 107 & 160 & 213 & \multirow[t]{2}{*}{0.40} & $\mathbf{V}_{w}$ & 0 & 107 & 213 & 320 & 427 \\
\hline & $V_{\text {NAPL }}$ & 213 & 160 & 107 & 53 & 0 & & $\mathbf{V}_{\text {NAPL }}$ & 427 & 320 & 213 & 107 & 0 \\
\hline
\end{tabular}


bution (Hilrost, 1998; Coppola et al., 2013). For an homogeneous and isotropic medium, a can be assumed equal to 0.5 (Alharti et al., 1986) and the mixing model is then referred to as the complex refractive index model (CRIM, e.g. Hiusman et al., 2003). The CRIM model does not account for the microgeometry of the components. However, despite this limitation, and the apparent simplicity of using the CRIM model, remarkably good agreement was found in modeling the dielectric properties of geological materials (Knight, 2001) and soil-waterNAPL mixture (Francisca and Montoro, 2012).

For mixtures of soil and water, the CRIM formula yields:

$$
\varepsilon_{s w}^{\prime}=\left[(1-\phi) \varepsilon_{s}^{\prime \alpha}+\phi \varepsilon_{w}^{\prime \alpha}+\phi(1-S) \varepsilon_{a}^{\prime \alpha}\right]^{1 / \alpha}
$$

where $\varepsilon_{s w}^{\prime}$ is the permittivity of soil-water mixture, $\varepsilon_{s}^{\prime}, \varepsilon_{w}^{\prime}, \varepsilon_{a}^{\prime}$ are the permittivities of soil particles, water and air respectively, $S$ is the degree of saturation and $\phi$ is the porosity of the sample.

Similarly for soil-organic mixtures, the CRIM formula becomes:

$$
\varepsilon_{s N A P L}^{\prime}=\left[(1-\phi) \varepsilon_{s}^{\prime \alpha}+\phi S \varepsilon_{N A P L}^{\prime \alpha}+\phi(1-S) \varepsilon_{a}^{\prime \alpha}\right]^{1 / \alpha}
$$

where $\varepsilon_{\text {SNAPL }}^{\prime}$ is the permittivity of the soil-NAPL mixture and $\varepsilon_{N A P L}$ is the permittivity of NAPL. Mixtures of soil particles, water, NAPL and air can be considered as mixtures of soil-air and water (equation 4) with soilair and NAPL (equation 5):

$$
\varepsilon_{s w-S N A P L}^{\prime}=\left[\beta \varepsilon_{s N A P L}^{\prime \alpha}+(1-\beta) \varepsilon_{s w}^{\prime \alpha}\right]^{1 / \alpha}
$$

where $\varepsilon_{s w-N A P L}^{\prime}$ is the permittivity of the soil-water-NAPL mixture and $b$ is the relative volume of NAPL $\left(\theta_{N A P L}\right)$ in water $\left(\theta_{w}\right)$ :

$$
\beta=\theta_{\text {NAPL }} /\left(\theta_{\text {NAPL }}+\theta_{w}\right)
$$

\section{Results and discussion}

Figure 3 shows a comparison between the measured dielectric permittivity and CRIM models (equations 4-5), fitted to the experimental data, corresponding to fully uncontaminated soil and fully contaminated soil respectively, as a function of the volumetric fluid content in the samples $\left(\theta_{f}=\theta_{w}\right.$ or $\left.\theta_{N A P L}\right)$.

In the CRIM model, to achieve accurate modeling, we adopt for the dielectric permittivity of the solid phase $\left(\varepsilon_{s}^{\prime}\right)$ a value of 4.18 , measured with the immersion method (Robinson et al., 2003; Kameyama and Miyamoto, 2008), which is, until recently the most common method for measuring $\varepsilon_{s}^{\prime}$ of soils. Figure 3 shows that: i) dielectric permittivity

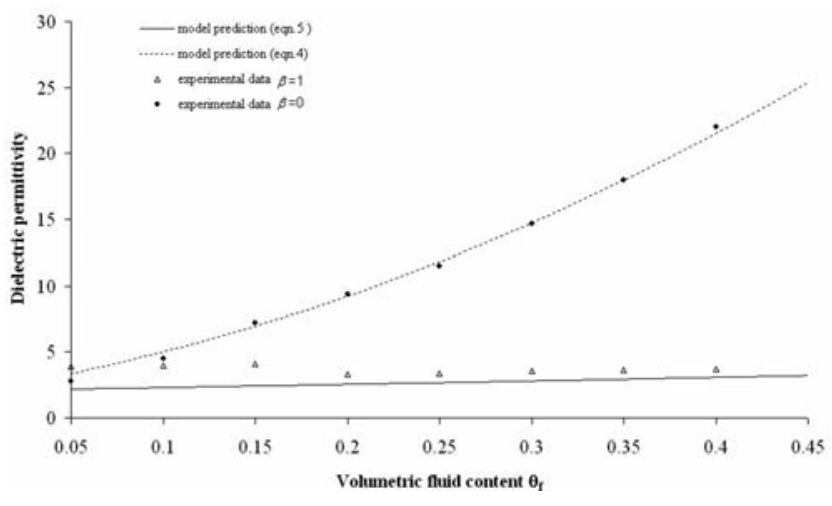

Figure 3 Effect of volumetric fluid content $\left(\theta_{f}\right)$ on dielectric permittivity of soil-water $\left(\varepsilon_{s w}^{\prime}\right)$ and soil-water-NAPL $\left(\varepsilon_{s N A P L}^{\prime}\right)$ mixtures. increases with volumetric content of fluids $\theta_{f}\left(=\theta_{w}\right.$ or $\left.\theta_{N A P}\right)$, while the presence of NAPL reduces the dielectric permittivity of the soil. The observed higher and lower dielectric permittivity values of the soilwater and soil-NAPL mixtures can be attributed here respectively to the presence of a larger amount of polar molecules in soil-water mixtures and to the non-polar nature of NAPL molecules in the soil-NAPL mixture, ii) the agreement of the CRIM model (equation 4) to the experimental data is fairly acceptable, iii) the CRIM model (equation 5) tends to underestimate the dielectric permittivity in the case of contaminated soil with NAPL (in particular in the range $0<\theta_{f}<0.2$ ); obtained differences, even small, may arise from experimental errors and from adopted values of $a=0.5$.

The model as given by Francisca and Montoro (equation 6), was then evaluated for different volume fractions of NAPL $(b=0.75,0.5,0.25)$ and the resulting curves were plotted together with experimental data in Figure 4 as a function of volumetric fluid content $\theta_{f}\left(=\theta_{N A P L}+\theta_{w}\right)$ in the soil samples. The model is adequate to forecast the dielectric permittivity only for values of volumetric fluid content $\left(\theta_{f}\right)$ greater than 0.20 ; notice that the slope of the curves becomes steeper as the NAPL content $(b)$ in the pore fluids decreases.

The volumetric content of NAPL $\left(\theta_{N A P L}\right)$, at a fixed, and thus known volumetric fluid content $\theta_{f}$, can be computed from equations 6 and 7 , deriving $\varepsilon^{\prime}{ }_{S N A P L}, \varepsilon^{\prime}{ }_{s w}$ from Figure 3, and the dielectric permittivity measured in the contaminated soil $\varepsilon_{s W-S N A P L}^{\prime}$. Parameters can be early obtained either in laboratory or in the field. Additionally Figure 4 can be very useful during an in situ remediation process to monitor the removal process.

Figure 5 presents a 1:1 plot for estimated and measured dielectric permittivity values to verify the accuracy of the dielectric mixing model (equation 6). The model adopted, showed that the estimated dielectric permittivity values were reasonable close to the measured, meaning that with TDR methodology it is possible to achieve sufficient accuracy in predicting the presence of a contaminant, mixed with water, in the soil, that is, the root mean square error (RMSE), is $0.719,0.584,0.438$, $0.413,0.267$ for $b=1,0.75,0.5,0.25,0$ respectively. Figure 6 reveals the effects of flushing volumes $N_{f}$ on measured dielectric permittivity $\left(\varepsilon^{\prime}\right)$ for the two samples initially contaminated with oil. As the flushing flow began to displace oil, the $\varepsilon$ ' increased because of the larger dielectric permittivity of the washing solution. As the solution continued to flow, the rate of increase of $\varepsilon^{\prime}$ lessened and asymptotically approaches a constant value. This constant value was reached after displacing approximately 15 times the total flushing volume $N_{f}$ in the column.

This steady-value was less than that obtained when the soil samples

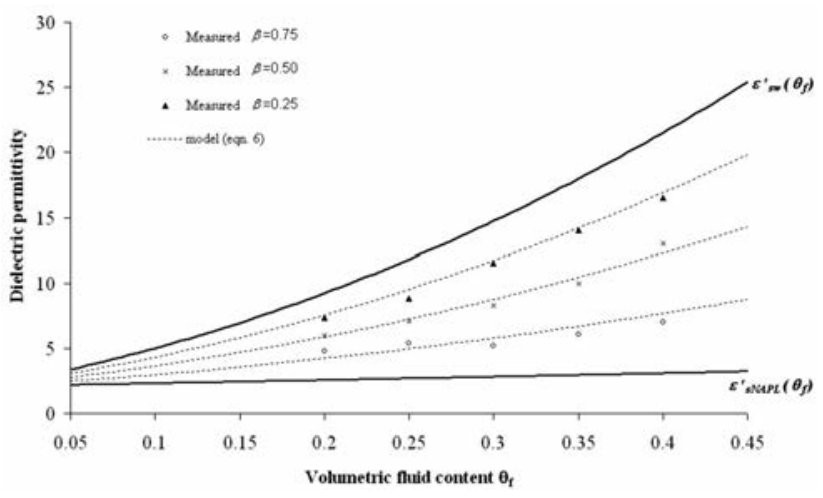

Figure 4. Dielectric permittivity of soil-water-NAPL mixtures $\left(\varepsilon_{s w-N A P L}^{\prime}\right)$ for different volumetric fluid contents $\left(\theta_{f}\right)$ and volume fractions of NAPL $(\beta)$. 


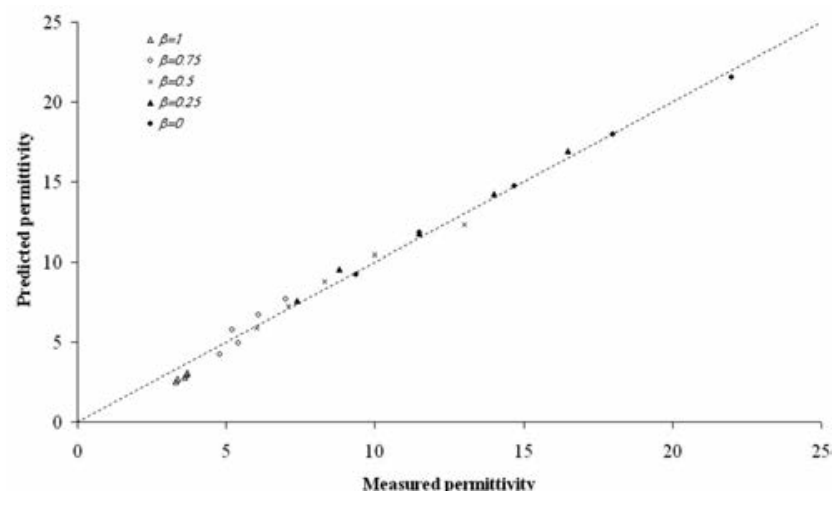

Figure 5. Relationship between calculated and measured dielectric permittivity $\left(\varepsilon_{s w-N A P L}^{\prime}\right)$ at different $\beta$ values.

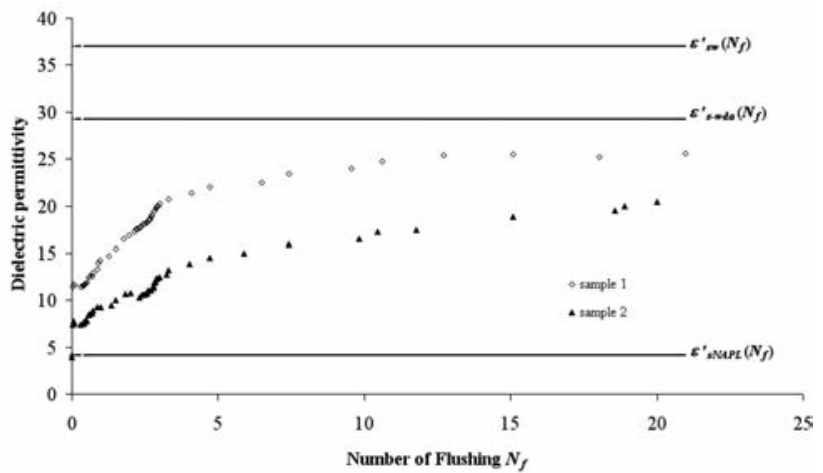

Figure 6. Dielectric permittivity of oil-contaminated soil samples, subjected to flushing with water-detergent-alcohol (sample 1) and distilled water (sample 2) washing solutions.

Table 3: Volumes of NAPL recovered at different $\mathrm{Nf}$ values, for each washing solution.

\begin{tabular}{|c|c|c|c|}
\hline \multicolumn{4}{|c|}{ Volume (\%) of NAPL Removed by: } \\
\hline Number of Flushing $N_{f}$ & Water-Detergent-Alcohol & Water & Number of Flushing $N_{f}$ \\
\hline 0.00 & 0.00 & 0.00 & 0.00 \\
\hline 0.02 & 9.07 & 18.5 & 0.05 \\
\hline 0.40 & 36.21 & 18.5 & 0.38 \\
\hline 0.51 & 37.11 & 19.2 & 0.51 \\
\hline 0.72 & 39.98 & 22.33 & 0.86 \\
\hline 0.90 & 42.49 & 23.97 & 1.47 \\
\hline 1.49 & 47.60 & 27.16 & 2.10 \\
\hline 2.19 & 56.78 & 28.35 & 2.80 \\
\hline 2.44 & 58.90 & 31.63 & 2.92 \\
\hline 2.63 & 60.50 & 32.85 & 3.30 \\
\hline 2.79 & 63.02 & 36.18 & 4.72 \\
\hline 3.31 & 67.30 & 39.23 & 7.43 \\
\hline 6.49 & 73.70 & 43.39 & 10.45 \\
\hline 10.61 & 80.20 & 50.89 & 15.15 \\
\hline 15.08 & 86.00 & 53.66 & 18.90 \\
\hline 21.30 & 86.72 & 55.88 & 20.10 \\
\hline
\end{tabular}

were completely saturated only by flushing solutions. This differences in values is due to oil trapped in soil pores. Contaminated sample (sample 1), flushed with a solution of water, detergent and methanol (wda), yields higher values of measured dielectric permittivity, as compared to the sample (sample 2) flushed with only distilled water. This effect was attributed to the potential of detergent and alcohol reducing the soil interfacial tension and contact angle. Finally a comparison of oil removed in soil samples, from direct volume measurements of the immiscible fluid in the discharge, is given, in Table 3, for the applications.

Table 3 clearly reveals that the inclusion of detergent and alcohol in the displacing fluid improves the removal efficiency considerable.

\section{Conclusions}

From the results of our experiment it can be concluded as follows: i) the dielectric properties of contaminated soil were analyzed using mixing models extended from two to three and four components. The models that better represent the dielectric properties of contaminated soil are the models proposed by Francisca and Montoro; ii) the curves of dielectric permittivity obtained from contaminated soil and different volume of water $\left(\theta_{w}\right)$ and NAPL $\left(\theta_{N A P L}\right)$, were considered as upper and lower bounds respectively. The amount of contaminant in the soil can be inferred from the plots of Figure 3 and 4 or with the aid of mixing models. In any case 
the volumetric fluid content $\theta_{f}$ must be known in advance; and iii) removal of oil during flushing, produced an increment in soil dielectric permittivity which allows evaluating the evolution of NAPL saturation degree during remediation processes and computing the organic contaminant content at different stages during remediation.

\section{References}

Ajo-Franklin J.B., Geller J.T., Harris J.M. 2006. A survey of the geophysical properties of chlorinated DNAPLs. J. Appl Geophys. 59, 177-189.

Alharti A., Lange J., Whitaker E. 1986 Immiscible fluid flow in porous media: Dielectric properties. J. Contam. Hydrol. 1, 107-118.

Allison L.E., 1965. Organic carbon. In A. Klute (ed.). Methods of Soil Analysis, Part 1, Madison, Agron. Monograph, vol 9, ASA and SSSA, pp. 1367-1378.

Carter D.L., Mortland M.M., Kemper W.D.M. 1986. Specific Surface. Methods of Soil Analysis, Part I. Physical and Mineralogical Methods-Agron, Monograph vol. 9 (2nd Edition), ASA and SSSA, Madison, 1986, p 413-423.

Chenaf D., Amara N. 2001. Time domain reflectometry for the characterization of diesel contaminated soils. Proc. Second Int. Symp. and Workshop on Time Domain Reflectometry for Innovative Geotechnical Applications (5-7 September 2001), Infrastructure Technology Institute, Northwestern University, Evanston, Illinois, USA.

Coppola A., Dragonetti G.,. Comegna A., Lamaddalena N.,. Caushi B., Haikal M.A., Basile A. 2013. Measuring and modeling water content in stony soils. Soil Till. Res. 128, 9-22.

Day P.R. 1965. Particle fractionation and particle-size analysis. In Black CA, editor, Methods of Soil Analysis, Part 1, Madison, American Society of Agronomy, pp 545-567.

Francisca M., Montoro M.A. 2012 Measuring the dielectric properties of soil-organic mixtures using coaxial impedance dielectric reflectometry. Journal of Applied Geophysics. 80, 101-109.

Gerhard J.I., Pang T., Kueper B.H. 2007. Time scales of DNAPL migration in sandy aquifers. Ground Water. 45, 147-157.

Haridy S.A., Persson M., Berndtsson R. 2004 Estimation of LNAPL saturation in fine sand using time-domain reflectometry. Hydrological Sciences. 49, 987-1000.

Heimovaara T.J., Bouten W., Verstraten J.M. 1994. Frequency domain analysis of time domain reflectometry waveforms, 2, A four-component complex dielectric mixing model for soils. Water Resour. Res. $30,201-210$.

Hilhorst M.A. 1998. Dielectric characterisation of soil. PhD dissertation, Wageningen Agricultural University.

Huisman J.A., Hubbard S.S., Redman J.D., Annan A.P. 2003. Measuring soil water content with ground penetrating radar: A review. Vadose Zone J. 2, 476-491.

Illangasekare H.T. 1998. Flow and entrapment of Non-Aqueous-Phase Fluids in heterogeneous soil formation. In. M.H. Selim, Ma L, (ed.). Physical nonequilibrium in soils. Michigan, Ann Arbor Press, pp 417-435.

Kameyama K., Miyamoto T. 2008. Measurement of solid phase permittivity for soils by time domain reflectometry. European Journal of Soil Science. 59, 1253-1259.

Knight R. 2001. Ground penetrating radar for environmental applications. Annu. Rev. Earth Planet Sci. 29, 229-255.

Ledieu J., De Bidder P., De Clerck P., Dautrebande S. 1986. A method of measuring soil moisture by time-domain reflectometry. J. Hydrol. 88, 319-328.

Jury W.A., Horton R. 2004. Soil Physics. New Jersey, John Wiley \& Sons.

Mercer J.W., Cohen R.M. 1990. A review of immiscible fluids in the subsurface: properties, models, characterization, and remediation. J. Contam. Hydrol. 6, 107-163.

Mohamed A.M.O., Said R.A. 2005. Detection of organic pollutants in sandy soils via TDR and eigendecomposition. J. Contain. Hydrol. 76, 235-249.

Moroizumi T., Sasaki Y. 2006. Estimating the nonaqueous-phase liquid content in saturated sandy soil using amplitude domain reflectometry. Soil Sci. Soc. Am. J. 72, 1520-1526.

Persson M., Berndtsson R. 2002. Measuring nonaqueous phase liquid saturation in soil using time domain reflectometry, Water Resour. Res. 38, doi: 10.1029/2001WR000523.

Redman J.D., Kueper B.H., Annan A.P. 1991. Dielectric stratigraphy of a DNAPL spill and implications for detection with ground penetrating radar. Ground Water Monitoring and Geophysical Methods, 5th National Outdoor Action Conference, Natl. Ground Water Assoc., Las Vegas, Nev.

Redman J.D., DeRyck S.M. 1994. Monitoring non-aqueous phase liquids in the subsurface with multilevel time domain reflectometry probes. Proc Symp. on Time Domain Reflectometry in Environmental, Infrastructure, and Mining Applications, Evanston, IL. Spec. Publ. SP19-94. U.S. Bur. of Mines, Washington, DC.

Roth K., Schulin R., Fluhler H., Attinger W. 1990. Calibration of time domain reflectometry for water content measurements using a composite dielectric approach. Water Resour. Res. 26, 2267-2273.

Topp C.G., Davis J.L., Annan A.P. 1980 Electromagnetic determination of soil water content: measurements in coaxial transmission lines. Water Resour. Res. 16, 574-582.

van Dam R.L., Borchers B., Hendrickx J.M.H. 2005. Methods for prediction of soil dielectric properties: a review. available on http//www.ees.nmt.edu/hydro/landmine.

Robinson D.A., Jones S.B., Wraith J.M., Or D. 2003 A review of advances in dielectric and electric conductivity measurements using time domain reflectometry, Vadose Zone J. 2, 444-475. 